\title{
www.czasopisma.pan.pl \\ Method and Apparatus for Assessing the Properties of Slags
}

\author{
S. Biernat ${ }^{\text {a }}$, A.W. Bydałek ${ }^{\mathrm{a}, \mathrm{b}, *}$, W. Wołczyński ${ }^{\mathrm{c}}$, M. Holtzer $^{\mathrm{d}}$ \\ ${ }^{a}$ State Higher Vocational School in Głogów, Głogów, Polska \\ ${ }^{b}$ University of Zielona Góra, Faculty of Mechanical Engineering, ul. Podgórna 50, 65-246 Zielona Góra, Polska \\ ${ }^{\mathrm{c}}$ Institute of Metallurgy And Materials Science of Polish Academy Of Sciences, ul. Reymonta 25, 30-059 Kraków, Poland \\ ${ }^{\mathrm{d}}$ AGH University of Science and Technology, Faculty of Foundry Engineering, Reymonta 23, 30-059 Krakow, Poland \\ *Corresponding author. E-mail address: adam_bk@poczta.onet.pl
}

Received 07.04.2017; accepted in revised form 07.06.2017

\begin{abstract}
A special Slag-Prop $\mathrm{Cu}$ database has been developed to archive data from laboratory and industrial tests related to post-reduction slags. In order to enrich the data areas, it was decided to design a system for measuring the temperature of the liquid slag and its viscosity. Objectives of research work are to gather information on the properties of post-slags such as the temperature of liquid slag and its viscosity. The discussed issues are especially important in the foundry practice. Designed research stand and using of database applications can greatly facilitate the work of metallurgists, foundrymen, technologists and scientists. The viscosity measurement was developed and presented earlier. The author's analytical methodology was supplemented by a thyristor measuring system (described in the article). The system temperature measurement can be performed simultaneously in 3 ways to reduce the measurement error. Measurement of the voltage $\mathrm{mV}$ using the Seebeck effect can be measured throughout the entire range of thermocouple resistance, up to $1300{ }^{\circ} \mathrm{C}$. Direct temperature measurement ${ }^{\circ} \mathrm{C}$ - measurement only below $1000{ }^{\circ} \mathrm{C}$. Additional measurement - the measurement can also be read from the pyrometer set above the bath. The temperature and the reading frequency depend on the device itself. The principle of measurement is that in a molten metal / slag crucible, we put a N-type thermocouple. The thermocouples are hung by means of a tripod above the crucible and placed in a crucible. The thermocouple is connected to a compensating line dedicated to this type of thermocouple. The cable is in turn connected to a special multimeter that has the ability to connect to a computer and upload results. Temperature measurement can be performed simultaneously in 3 ways to reduce the measurement error. The $\mathrm{Sn}-\mathrm{Pb}$ alloy has been subjected to testing for proper operation of the device. In this foot should be observed the supercooling of the liquid, which initiates the crystallization process and in which latent heat begins to exude raising the temperature until the coagulation temperature is reached.
\end{abstract}

Keywords: Environmental protection, Innovative materials and casting technologies, Laboratory station, Slags, Slag-prop

\section{Introduction}

During production and refining processes, a significant proportion of the metal passes to the slag. As indicated by laboratory tests, 11 to $16 \%$ of copper $\mathrm{Cu}$ alone can be present, $[1,2]$ whereas, according to Madej and Kucharski, more than $9 \%$ $\mathrm{Cu}$ copper can be present in the converter slag [3]. Slag modification treatments are necessary not only for the recovery of copper. The treatments also allow for further processing to recover precious materials such as silver, gold or platinum. Due to the very high weight of the process of copper removal from slag, the process improves through various technological additives, followed by evaluation of the efficiency of the slag $[4,5]$. 


\section{Analysis of the issue}

The Slag-Prop $\mathrm{Cu}$ database [6,7] was prepared based of their physical, mechanical and technological properties, collected from their own research and literature. The database combines the information collected over the years of laboratory and industrial research. Measurement of coagulation kinetics is a well-known method [8-10]. The results of the slag solidification kinetics analysis are missing. In order to supplement the database with these results, a measuring device was designed and constructed. In addition, in order to enrich the data areas, it was decided to design a system for measuring the temperature of the liquid slag and its viscosity. The viscosity measurement was developed in the previously developed analytical methodology, which is supplemented by a thyristor measuring system. The thyristor system is a component of a multimeters allowing you to read voltage and temperature values for a melt or slag. Due to the high class of equipment, very accurate results are obtained.

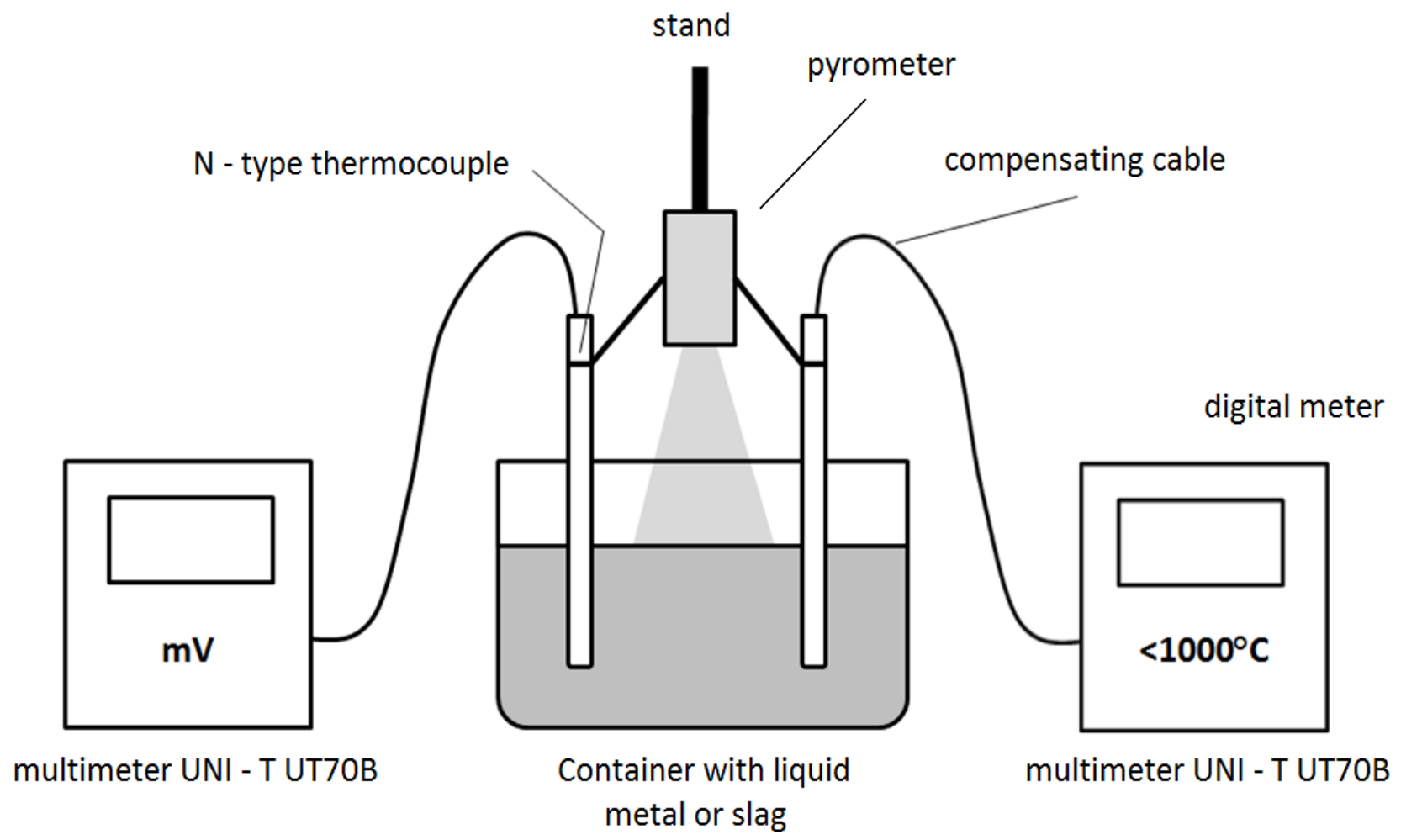

Fig. 1. Scheme of a laboratory stand for measuring the thermal analysis of liquid metals or slags

\subsection{Measuring system}

In the above figure (Fig. 1) is shown a scheme of a system for measuring the temperature of a liquid metal or slag. The design of the laboratory stand has been designed so that it can be carried out not only in the laboratory, but easily transported to a factory for easy measurement. The laboratory stand allows for a simple thermal analysis. The method of curve of heating it consists of to continuous and dynamic temperature testing of a heated or chilled sample at constant speed. Thanks to the research, curves of heating of the given sample, representing the temperature value as a function of time, are obtained. The basic capabilities of the constructed system are the melting and crystallization of metals and alloys, the possibility of preparing phase equilibrium diagrams of the tested substances as well as the ability to determine the degree of purity of a substance by knowing its melting temperature. The basic layout elements are listed in table 1 (Table 1). The working elements are N-type thermocouple with $300 \mathrm{~mm}$ probe and $100 \mathrm{~cm}$ compensation cable to connect them to the appropriate meter.
Table 1.

A summary of the elements used for the construction of the laboratory stand

\begin{tabular}{llll}
\hline No. & Name & Quantity & Type \\
\hline 1. & Thermocouple & 2 & N - type \\
\hline 2. & Crucible & 2 & steel \\
\hline 3. & Multimeter & 2 & UNI-T UT70B \\
\hline 4. & Pyrometer & 1 & GM 900
\end{tabular}

According to their manufacturer they are made of a nicrosil alloy and allow for temperature measurement from $-230^{\circ} \mathrm{C}$ to + $1300^{\circ} \mathrm{C}$.Nicrosil alloy is nickel and chromium alloy. It has a very high sensitivity (about $39 \mu \mathrm{V} /{ }^{\circ} \mathrm{C}$ ) and very good thermal stability, comparable to platinum thermocouples. Due to its affordable price it was chosen for research. It is worth to pay attention to the crucible with the test sample, which has been made in steel, and the walls in the narrowest place are $1 \mathrm{~cm}$ thick. Thanks to such 
construction, the sample can not only be safely placed in a vessel but also melted in a laboratory oven without fear of damaging the vessel itself. In addition, the process of cooling the material in this case is much longer, allowing for a more precise recording of the thermal changes occurring in the system. Thermocouples are connected to UNI-T UT70B multimeters. The system uses 2 different measurements to eliminate the measurement error of the sample being tested. The first of the multimeters performs direct measurement of the temperature read through the probe. The measuring range of this device is limited to $1000^{\circ} \mathrm{C}$, but nothing prevents the device from being connected to a device with a wider measuring scale. The second probe is in turn connected to the other meter. Here, the Seebeck phenomenon is used, which is a thermoelectric phenomenon involving the formation of an electromotive force in a circuit whose two metals are at different temperatures. In this case, there is a direct measurement of the voltage expressed in $\mathrm{mV}$. The measurement made by this method can be carried out throughout the measuring range of the thermocouple, i.e. to $1300^{\circ} \mathrm{C}$ and above. In order to convert voltages to temperatures, the thermocouple can be calibrated in an electric furnace by studying its behavior relative to the reference element.

Finally, a GM 900 type pyrometer was added to the entire system. This device can read the temperature of the top layer of the liquid slag and its reaction surface after being removed from the furnace. From the point of view of the system liquid metal - slag atmosphere, the phenomenon of oxidation occurs here most intensely. The following table (Table 2) gives the measuring ranges of the device for contactless temperature measurement with measuring accuracy.

Table 2

Set of measuring ranges and measuring accuracy for non-contact temperature measurement

\begin{tabular}{ccc}
\hline No. & Range $\left({ }^{0} \mathrm{C}\right)$ & $\begin{array}{c}\text { Measuring } \\
\text { accuracy }\end{array}$ \\
\hline 1. & $-50 \sim 0$ & $\pm 3^{0} \mathrm{C}$ \\
\hline 2. & $0 \sim 100$ & $\pm 1,5^{0} \mathrm{C}$ \\
\hline 3. & $100 \sim 900$ & $\pm 1,5 \%$ \\
\hline
\end{tabular}

\subsection{Database}

The material base has been introduced as well as it has the ability to independently add various information regarding the physicochemical properties of certain slag mixtures such as melting point, wetting, surface tension, viscosity, electrical conductivity and others. Each specific property refers to the specific composition of the slag mix. The material database also has experimental data obtained from own research. Not only thermal analysis but also DTA and TG research. On this basis, it will be easy to obtain information on the refining capacity of the selected slag composition. The database can be used not only to search for optimum conditions meeting technological and construction criteria. It may also serve as a basis for setting new scientific orientations. Essential, therefore, is that the database is openness and can be filled up with new data obtained in laboratory or industrial environments.

At the beginning of the operation of the program, the user indicates the kind of analysis he is interested in. That is, it must indicate whether it will want to check the physicochemical and refining characteristics of a certain type of slag, or whether it will seek areas with given physicochemical properties, with a final indication of refining capacity. After indicating the type of analysis, it is assumed that in the next step it will be possible to determine the type of slag the user is interested in and determine the additional parameters of the layout (e.g. kind of atmosphere).If a user in the first step declares to search for information on the specified area after specifying all the necessary information, he or she will be able to point to an interesting field where the results of the analysis of the area will be presented.

If a user wanted to search for areas that matched criteria he must specify the type of expected properties and then enter them into the program. Then the base content filtering will be performed. Finally, the search results will be displayed to the user. In addition, the user will be able to check the orientation of the location in which the sophisticated area is located or whether it has additional physicochemical properties.

Irrespective of the type of analysis, the user must specify more precisely the type of slag he / she would like to obtain information and specify the type of atmosphere in which the process will be carried out. It was decided that the program would include a group of oxide-based slags. The basic system is a 3-component $\mathrm{Al}_{2} \mathrm{O}_{3}-$ $\mathrm{CaO}-\mathrm{SiO}_{2}$ system. Another 4 components can be added to this base system, which can radically change the physicochemical properties of the system. It was assumed that oxide compounds would be considered here $\left(\mathrm{MgO}, \mathrm{B}_{2} \mathrm{O}_{3}, \mathrm{Na}_{2} \mathrm{O}\right)$, and chloride $(\mathrm{KCl}$, $\mathrm{NaCl})$ and fluoride $\left(\mathrm{KF}, \mathrm{KF}_{2}, \mathrm{NF}_{2}\right)$. It was also decided to add two oxide components $\left(\mathrm{B}_{2} \mathrm{O}_{3}\right.$ and $\left.\mathrm{Na}_{2} \mathrm{O}\right)$ to the base system, thus forming a five-component slag mixture.

The user must also choose the type of atmosphere in which the melting process will be performed. The type of atmosphere can in extreme ways influence the properties of the slag. This is why 3 different types of atmosphere are considered here: neutral, oxidizing and reducing.

After declaring all the necessary information, the user can go to indicate the area of the particular system.

The search for the physicochemical properties of a particular slag mix may not be sufficient in the search for an area meeting certain criteria. In order to simplify the optimal compositions of the described extraction coatings, the second option of the program is used - enter the criteria.

The user, after declaring the initial values, is transferred to the place where he has to make an appropriate choice of physicochemical properties. The user may indicate here any physicochemical properties that you would like to search for. These include, but are not limited to: melting point, wettability, surface tension, viscosity, or electrical conductivity. In addition, it can narrow down the search area by introducing an approximate weight ratio of the ingredients of the refining mixtures. 


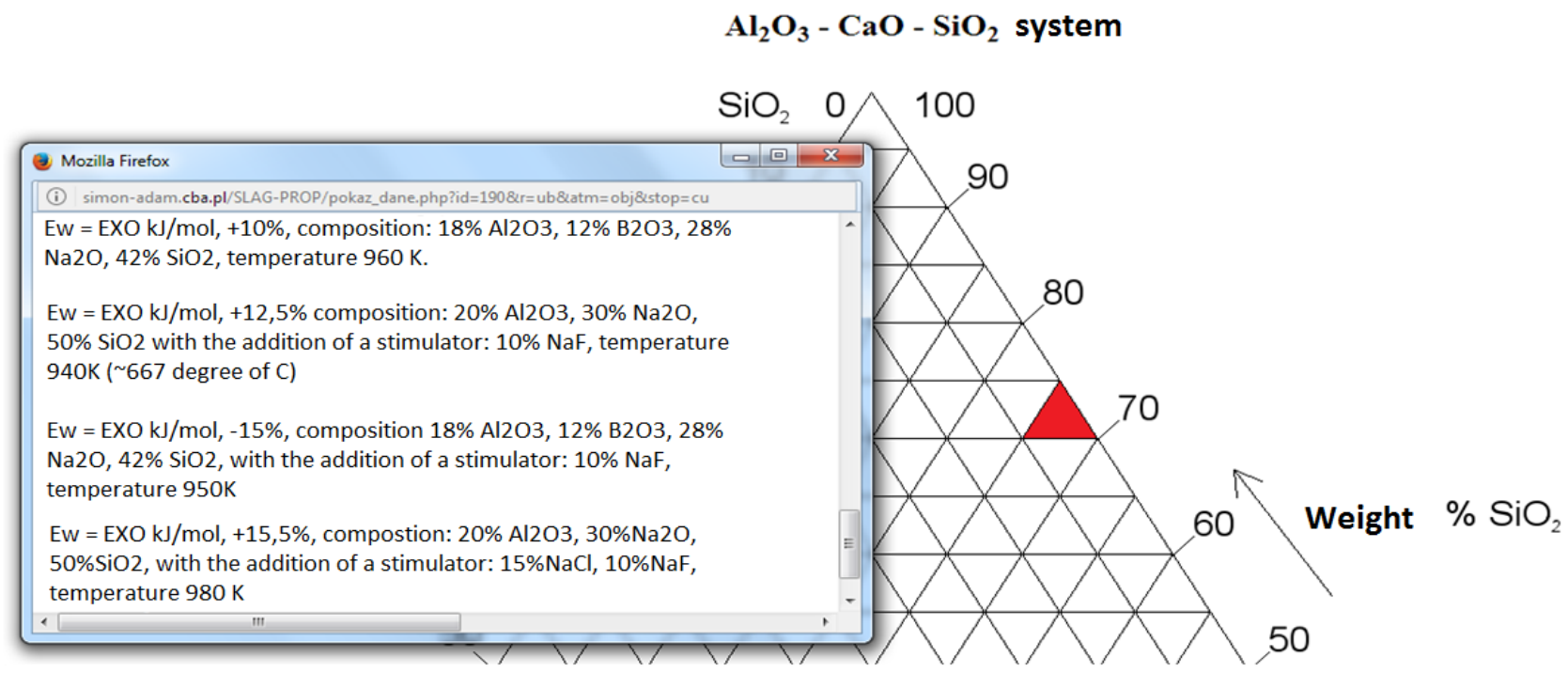

Fig. 2. Fragment of slag mix description from Slag - Prop database (screenshot of Slag - Prop program). Numbers in the figure show the percentage composition of the component. An additional window displays information on the refining and physicochemical properties for area marked in red.

In the above figure (Fig. 2), a fragment of the exemplary 3component mixture - $\mathrm{Al}_{2} \mathrm{O}_{3}-\mathrm{CaO}-\mathrm{SiO}_{2}$, designated with reference number 190 is shown. This number corresponds to the slag mix composition containing $25-30 \% \mathrm{Al}_{2} \mathrm{O}_{3}, 70-75 \% \mathrm{SiO}_{2}$ and up to $5 \%$ $\mathrm{CaO}$.
In the next figure (Fig. 3) there is a result of the search of the standard areas of the $\mathrm{Al}_{2} \mathrm{O}_{3}-\mathrm{CaO}-\mathrm{SiO}_{2}$ slag mix, the weight ratio of which allows the melting point of the system to be below or exactly $1000^{\circ} \mathrm{C}$, using the appropriate additives, which were reflected in the database. In this case, 6 areas were found meeting the criteria.

\begin{tabular}{|c|c|c|c|c|c|c|c|c|c|c|c|c|c|c|c|c|}
\hline \multicolumn{17}{|c|}{ Areas meeting the criteria } \\
\hline \multicolumn{17}{|c|}{ Type of slag: $\mathrm{Al}_{2} \mathrm{O}_{3}-\mathrm{CaO}-\mathrm{SiO}_{2}$} \\
\hline \multicolumn{17}{|c|}{ Characteristics of found areas: } \\
\hline $\begin{array}{l}\text { Temp } \\
\min \end{array}$ & $\begin{array}{l}\text { Temp } \\
\max \end{array}$ & $\begin{array}{l}\text { Viscosity } \\
\min \end{array}$ & $\begin{array}{l}\text { Viscosity } \\
\max \end{array}$ & $\begin{array}{l}\text { Wettability } \\
\text { min }\end{array}$ & \begin{tabular}{|l} 
Wettability \\
max
\end{tabular} & \begin{tabular}{|l|} 
Surface \\
tension \\
min \\
\end{tabular} & $\begin{array}{l}\text { Surface } \\
\text { tension } \\
\text { max }\end{array}$ & $\begin{array}{l}\text { Elect. conduct } \\
\min \end{array}$ & $\begin{array}{l}\text { Elect. conduct } \\
\max \end{array}$ & \begin{tabular}{|l|} 
Amount \\
$\mathrm{A} 12 \mathrm{O} 3$ \\
$\mathrm{~min}$.
\end{tabular} & $\begin{array}{l}\text { Amount } \\
\mathrm{A} 12 \mathrm{O} 3 \\
\text { max. }\end{array}$ & $\begin{array}{l}\mathrm{Am} \cdot \\
\mathrm{CaO} \\
\mathrm{min} .\end{array}$ & \begin{tabular}{|l} 
Am. \\
CaO \\
max.
\end{tabular} & $\begin{array}{l}\text { Am. } \\
\mathrm{SiO} 2 \\
\text { min. }\end{array}$ & $\begin{array}{l}\mathrm{Am} . \\
\mathrm{SiO}_{2} \\
\max .\end{array}$ & id \\
\hline${ }^{\circ} \mathrm{C}$ & ${ }^{\circ} \mathrm{C}$ & $\mathbf{P}$ & $\mathbf{P}$ & $\circ$ & $\circ$ & $\mathbf{N} / \mathbf{m}$ & $\mathrm{N} / \mathrm{m}$ & $\mathrm{Ohm}^{-1} \mathrm{~cm}^{-1}$ & $\mathrm{Ohm}^{-1} \mathrm{~cm}^{-1}$ & $\%$ & $\%$ & $\%$ & $\%$ & $\%$ & $\%$ & - \\
\hline$\underline{667}$ & 1700 & * & $=*$ & $*$ & $* *$ & 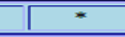 & $* *$ & 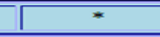 & $1 \%$ & 25 & 30 & 0 & 5 & 70 & 75 & $\underline{190}$ \\
\hline$\underline{1000}$ & 1900 & * & $* *$ & * & $* *$ & 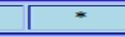 & $* *$ & 0.0 & 0.3 & 10 & 15 & 55 & 60 & 25 & 30 & 307 \\
\hline$\underline{977}$ & 1700 & 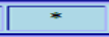 & $* *$ & 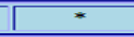 & $* *$ & 0.411 & 4.809 & 0.1 & 0.3 & 10 & 15 & 25 & 30 & 60 & 65 & $\underline{180}$ \\
\hline$\underline{527}$ & 1500 & * & $* * *$ & 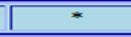 & $* *$ & 0.401 & 0.457 & 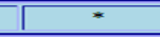 & $* *$ & 20 & 25 & 15 & 20 & 55 & 60 & 368 \\
\hline$\underline{\underline{*}}$ & $1800^{*}$ & 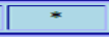 & $* *$ & * & $* *$ & $*$ & $* *$ & * & $* *$ & 40 & 45 & 0 & 5 & 55 & 60 & $\underline{166}$ \\
\hline \pm & $1830^{*}$ & * & $* *$ & "* & $* *$ & * & $* *$ & 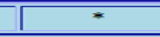 & $* *$ & 50 & 55 & 0 & 5 & 45 & 50 & $\underline{145}$ \\
\hline
\end{tabular}

Fig. 3. Database search results for slags, whose melting point does not exceed $1000^{\circ} \mathrm{C}$ (screenshot of Slag - Prop program)

\section{Results of tests}

After the construction of the laboratory stand, a number of studies were carried out. The first sample that was investigated was alloy: $\mathrm{Sn}(60 \%)$ and $\mathrm{Pb}(40 \%)$. Figure 4 shows the temperature graphs that were obtained in this experiment. 
a)

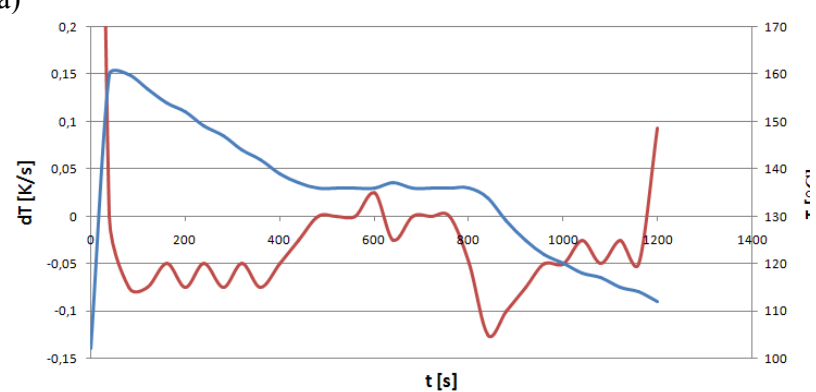

b)

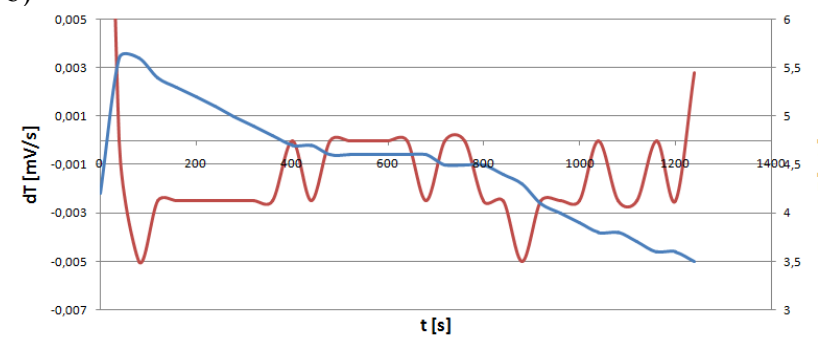

c)

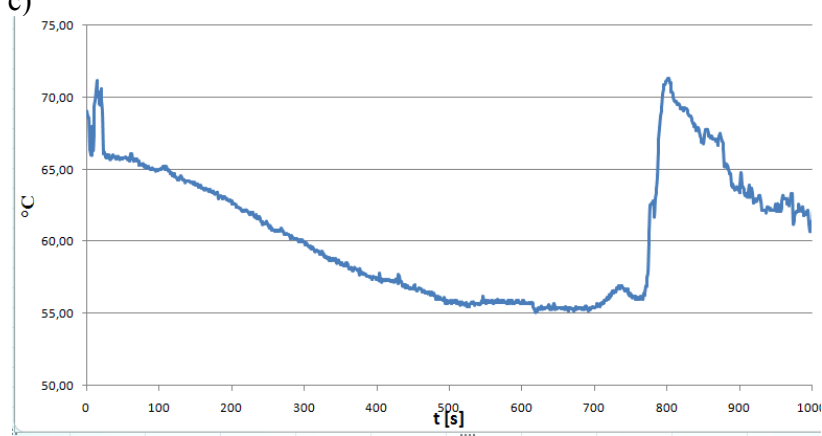

Fig. 4. The tin $\mathrm{Sn}(60 \%)$ and lead $\mathrm{Pb}(40 \%)$ alloy; a) temperature graph - thermocouple immersed in the bath b) voltage graph

(Seebeck phenomenon) - thermocouple immersed in the bath c) temperature graph on the surface of the bath - pyrometer

As can be seen in the graphs inside the metallic bath, the solid phase nucleation occurs near $140{ }^{\circ} \mathrm{C}$ (Fig. $4 \mathrm{a}$ and $4 \mathrm{~b}$ ). Here you can see the characteristic pitch of the graph, which confirms the voltage chart using the Seebeck effect (Fig. 4b).Interestingly, a temperature graph made using a pyrometer $(4 \mathrm{c})$ is shown - on surface of bath. As you can see the surface temperature of the bath drops to about $55^{\circ} \mathrm{C}$ and then starts to rise above $70^{\circ} \mathrm{C}$. The observed phenomenon can be explained by the intense formation of the oxide phase of the system at this point, which is an exothermic reaction which results in an increase in the heat released to the outside. Therefore, using the position and various combinations of metal alloys, it is possible to make phase diagrams for individual systems. In the next cycle of experiments the metallurgical slags were subjected to the tests. One of the investigated slags was the converter slag. Figure 5 (Fig. 5) shows the slag temperature graphs. a)

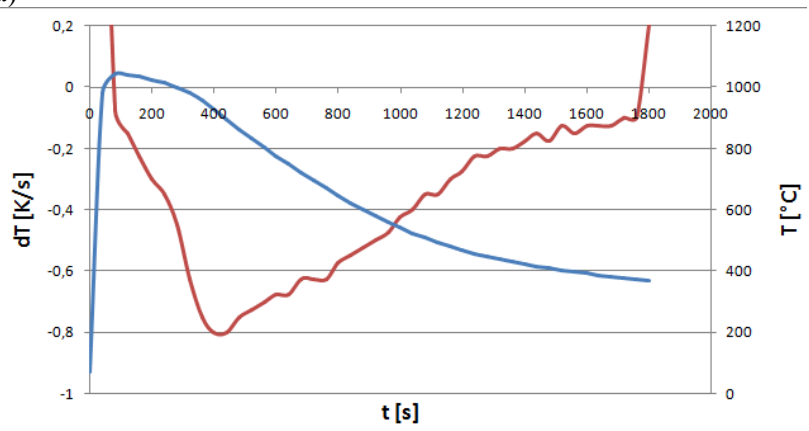

b)

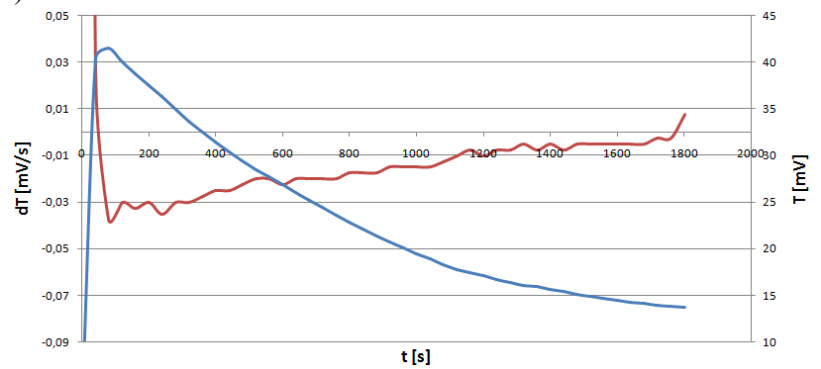

c)

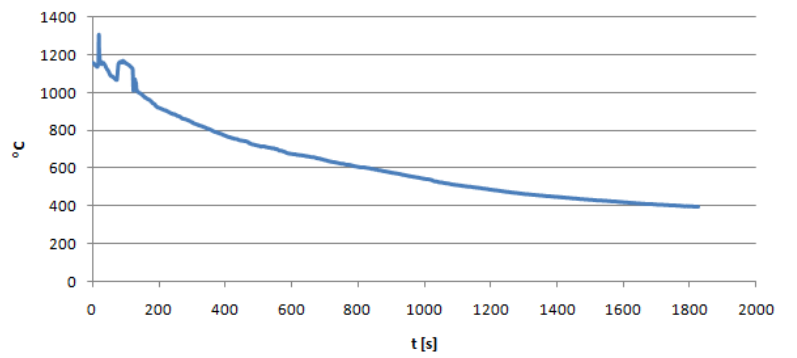

Fig. 5. The converter slag; a) temperature graph - thermocouple immersed in the bath b) voltage graph (Seebeck phenomenon) thermocouple immersed in the bath c) temperature graph on the surface of the bath - pyrometer

On the basis of slag investigations, its coagulation characteristics can be determined. It can be seen that the process of its solidification is significantly different from the solidification process of molten alloy or metal, which should be explained by the presence of glassy material. Slags are significantly different chemical composition and physicochemical properties. Slag in the liquid state is an ionic solution, also a strong electrolyte composed mainly of oxides. The pure metals represent only a small percentage of the system, but can be recovered using appropriate technologies and refining. Figure $5 \mathrm{a}$ and $5 \mathrm{~b}$ show the temperature changes occurring inside the liquid slag until it solidifies and reaches a temperature of about $400{ }^{\circ} \mathrm{C}$. Figure $5 \mathrm{c}$, in turn, represents the surface temperature of the sample. All the drawings show a gradual decrease in temperature without a temporary increase which is characteristic of glassy materials such as slag. 


\section{Summary}

By creating a laboratory stand and developing a research methodology, you can get comprehensive information on the physical, chemical, refining and technological properties of liquid slags, as well as metals and their alloys. With the 3-point temperature measurement, both the inside of the bath and its surface can provide not only a more comprehensive view of the temperature distribution of the system, but also to delete the possible measurement error. In turn, developed application with database allows to search the composition of slag mixtures for different physicochemical properties. In addition, data can be supplemented with additional information based on own research. The database itself contains a collection of different compositions of slag mixtures. Each layout is represented in the form of a Gibbs graph, which is divided into 400 equal areas. Each research area can be modified in any way by using appropriate stimulators and catalysts that can change its physicochemical properties. In this way, the range of values of a given property can be increased, thereby striving for the desired results. It should also be borne in mind that the physicochemical properties of slag mixtures, and in particular their refining capacity, have a great influence on the technological properties of the metals and their alloys. They allow for a more efficient way to obtain the desired product not only in terms of chemical composition, but also for gassing of the system, or the difficulty of removing the slag layer from the bath. This is especially important in foundry. Therefore, the position and use of database applications can greatly facilitate the work of metallurgists, foundries, technologists and scientists themselves.

\section{Acknowledgements}

This project was supported by the National Center for Research and Development under Grant No. PBS3/A5/45/2015

\section{References}

[1] Holappa, L. \& Taskinen, P. (2017). Process innovations and sustainability in Finnish metallurgical industries. Transactions of the Institutions of Mining and Metallurgy, Section C: Mineral Processing and Extractive Metallurgy. 126 (1-2), 70-80.ISSN (03717844).

[2] Karwan, T. (2013). Metallurgy of non-ferrous metal (in Polish). Kraków - Bukowno: Wydaw. Beltrani. ISBN (97883-913252-7-8)

[3] Madej, P. \& Kucharski, M. (2015). Influence of temperature on the rate of copper recovery from the slag of the flash directto-blister process by a solid carbon reducer. Archives of Metallurgy and Materials. 60(3A), 1663-1671. ISSN (23001909).

[4] Sarfo, P., Wyss, G., Ma, G., Das, A. \& Young, C. (2017) Carbothermal reduction of copper smelter slag for recycling into pig iron and glass. Minerals Engineering. 107, 8-19. ISSN (0892-6875).

[5] Fernández-Caliani, J.C., Moreno-Ventas, I., Bacedoni, M. \& Ríos, G. (2017). Mineral chemistry and phase equilibrium constraints on the origin of accretions formed during copper flash smelting. Minerals and Metallurgical Processing. 34 (1), 36-43. ISSN (0747-9182).

[6] Bydałek, A.W., Wołczyński, W., Bydałek, A., Schlafka, P. \& Kwapisiński, P. (2015). Analysis of separation mechanism of the metallic phase of slag in the direct-to-blister process, Archives of Metallurgy and Materials. 60(3), 2347-2353. ISSN (2300-1909).

[7] Schlafka, P., Bydałek, A.W., Holtzer, M. \& Wołczyński, W. (2016). The Influence of The Ionic Reactions on the Refining Secondary Raw Materials; Metalurgija, 55(4), 609-612. ISSN (0543-5846).

[8] Jura, Z. (2000). Method of crystallization heat definition in temperature function for metal alloys. Solidification of Metals and Alloys. 43(2), 299-302. ISSN (0208-9386)

[9] Park, J.H., Park, S., Han, X.-F. \& Yi, K.W. (2016). Numerical analysis on fluid flow and heat transfer in the smelting furnace of mitsubishi process for $\mathrm{Cu}$ refining. Metals and Materials International. 22(1), 118-128. ISSN (1598-9623).

[10] Dudyk, M., Wasilewski, P., Ciućka, T. \& Pezda, J. (1998). Simultaneous recording of crystallization process of aluminium alloys with ATD and AED methods. Archives of Metallurgy. 43(4), 321-328. ISSN (1733-3490). 